\title{
LA PRENSA CATÓlica CATALANA DE 1868 A 1900 (III)*
}

Solange HIBBS-LISSORGUES Universidad de Toulouse-Le Mirail

De 1881 a 1884 fracasaron los diferentes intentos, por parte del episcopado español así como de laicos, desde la prensa y las asociaciones religiosas, para poner un término a las disensiones internas de los católicos. El clima de cisma que León XIII intenta apaciguar con su encíclica Cum Multa de 1882 culmina, en 1884, con la publicación de lo que iba a convertirse en la biblia del integrismo: El liberalismo es pecado de Félix Sardá y Salvany.

En 1884, la virulencia de las campañas anti "mestizas" organizadas desde la prensa carlista y nocedalista agrava las tensiones existentes y afecta la cohesión del episcopado. Esta prensa se convierte en un "segundo poder religioso" y se arroga el papel de organizador de las masas católicas. Los contra-centenarios, las romerías y actos de adhesión a Pío IX y a León XIII así como las suscripciones populares a favor de los obispos más íntegros contribuyeron a transformar los diarios y revistas integristas en instrumentos de movilización ideológica. Publicaciones como El Siglo Futuro (1875-1936) de Cándido Nocedal y la Revista Popular, que hacían alarde de su purismo político-religioso, pretendieron ser los más fieles intérpretes de las tradiciones católicas del pueblo español. Aprovechando las libertades de expresión y de imprenta concedidas por la Constitución, emprendieron campañas de oposición al gobierno canovista y a la monarquía liberal.

La constitución de la Unión Católica de Pidal en 1881 reforzó el comportamiento intolerante de la Comunidad Tradicionalista que sospechaba de los fines políticos del proyecto.

A partir de aquel momento, la prensa se convirtió en el campo de batalla privilegiado de carlista e integristas.

* Continuación de lo publicado en nuestro número 9 (1993). 


\section{Católicos moderados y católicos intransigentes ante la unión católica de Pidal}

Desde 1876 hasta 1880, Pidal cuyo ideal era crear un partido político semejante al Zentrum alemán de Windhorst, había intentado, por medio de la prensa, atraer a los católicos que seguían a Cándido Nocedal ${ }^{1}$.

A partir de 1878 , varios factores propiciaron el proyecto de Pidal. La designación de Cándido Nocedal como director de la prensa carlista, en 1871, había sido muy mal acogida por los carlistas que temían la orientación intransigente y exclusivista de un hombre político que tenía mucho peso en el partido. Las divergencias estratégicas y doctrinales de prohombres del carlismo como Canga Argüelles y Navarro Villoslada, que dimitieron de la dirección de sus respectivos periódicos en 1872, habían contribuido a debilitar el partido carlista y anunciaban la grave crisis de 1888 (Gómez Aparicio, 1970, pág. 283).

En 1880, Pidal, que se oponía a la postura de total abstención política preconizada por Nocedal, quiso aprovecharse de las tensiones internas de la Comunión Tradicionalista y dirigió, desde las Cortes, un llamamiento a "las honradas masas carlistas" para que participasen a la vida política de la Restauración ${ }^{2}$. Por otra parte, la llegada de León XIII en 1878 como pontífice era un elemento favorable para promover un proyecto de unión de los católicos. Más conciliador y abierto a la sociedad contemporánea que Pío IX, el nuevo Papa preconizaba la colaboración del catolicismo con monarquías y gobiernos liberales. No veía con malos ojos la colaboración con "el mal menor" canovista ${ }^{3}$. Esta orientación conciliadora de León XIII contaba con el apoyo del Secretario de Estado del Papa, el Cardenal Rampolla, que fue Nuncio apostólico en España hasta 1887.

La situación de los católicos franceses iba a brindar una excelente oportunidad a Pidal para llevar a cabo su proyecto. En Marzo de 1880, Monseñor Freppel, obispo de Angers, dirigió un mensaje a los legitimistas franceses exhortándoles

1. En 1880 , en uno de los momentos álgidos de la contienda verbal que lo opone a Nocedal y a El Siglo Futuro, Pidal reivindica para la Iglesia ciertas libertades y afirma que todos los católicos deben emprender "la reconquista de la Sociedad que se nos va, y tenemos que hacerlo con los mismos medios de que se ha servido la Revolución para corromperla: [...] por las asociaciones, por todos los medios en fin, legítimos y adecuados al objeto" (Gómez Aparicio, 1970, pág. 314).

2. Este conocido discurso de Pidal ¿Qué esperáis?, que empezaba por una llamada a las honradas masas carlistas, fue comentado de manera muy crítica por la prensa carlista e integrista que lo consideró como una incitación por parte de Pidal para que los carlistas traicionasen la causa de Don Carlos.

3. León XIII incitó a los católicos a no permanecer al margen de la sociedad contemporánea y a utilizar las instituciones liberales a favor de la causa católica. Preconizó la unión de los católicos independientemente de cualquier opción política. Estas orientaciones, que tuvieron un profundo alcance social y político, fueron enunciadas en tres importantes encíclicas: la Cum Multa en 1882, la Inmortale Dei en 1885 y la Libertas en 1888. 
a unirse en contra de las leyes antirreligiosas adoptadas por el gobierno de Gambetta. Con el título "Reunir a los dispersos", El Fénix, cuya finalidad a partir de 1879 era dar una consistencia definitiva al proyecto de la Unión Católica, publicó en Junio de 1880 un artículo en el que felicitaba a Freppel. El autor del artículo era Ceferino Suárez Bravo, antiguo colaborador de El Siglo Futuro. En su artículo, Suárez Bravo acusaba a los intransigentes de obstruir la causa de los católicos con su abstención política (Campomar Fornieles, 1984, pp. 6465). La reacción de El Siglo Futuro y los ajustes de cuentas que se produjeron entre el antiguo colaborador del periódico integrista y Cándido Nocedal reflejaban claramente las divisiones que reinaban en las filas del partido carlista. Aprovechando esta situación, Pidal, después de su llamada de unión desde las Cortes (Junio 1880), envió un mensaje de felicitación a Freppel que fue firmado por personalidades de diferentes tendencias políticas ${ }^{4}$. En este mensaje se invitaba a todos los católicos, cualesquiera que fuesen sus compromisos políticos, a formar una unión contra el gobierno de Sagasta. Más tarde la misma carta, acompañada de una circular, fue enviada a todos los miembros del episcopado español.

En su circular, los promotores de la Unión Católica se declaraban conscientes de las polémicas que suscitaba el proyecto y de las reticencias que podían experimentar algunos miembros del episcopado ${ }^{5}$. Al declarar que no había incompatibilidades entre las opciones políticas de los católicos deseosos de entrar en la Unión y la defensa de la Iglesia, los firmantes de la circular presentaban a la Unión Católica como una amalgama muy flexible.

Al contestar a la circular de Pidal, algunos miembros del episcopado no ocultaron sus reticencias y hasta su declarada hostilidad. El primero en poner reparos al proyecto fue el arzobispo de Granada, Mr. Bienvenido Monzón. Temía que tal proyecto no hiciera más que ahondar las divisiones que ya existían en el campo de los católicos. Con tono profético, describía las repercusiones de un proyecto, demasiado elástico a su juicio, que podría llegar a ser "una nueva manzana de discordia que, arrojada al campo católico, llevaría la perturbación y división a todas partes, y hasta lograría introducirla en el clero y el Episcopado" (La Cruz, 1881c, I pág. 215).

4. Entre los firmantes de este mensaje cabe destacar personalidades carlistas y católicas a favor de la monarquía alfonsina: Ortí y Lara, Valentín Gómez, Leandro Herrero, redactor de El Fénix, el marqués de Viluma, Manuel Pérez Villamil, director de La Ilustración Católica, Menéndez Pelayo, etc.

5. "Nosotros mismos, por nuestra imperefección y flaqueza, acaso demos lugar a que no se nos entienda bien, ni se nos haga completa justicia; quizás demos o hayamos dado ocasión a que la ceguedad, la pasión o la malicia tergiversen nuestros propósitos y den torcida interpretación a nuestros actos" ("Circular de los representantes de la Unión Católica en Madrid a los Señores Obispos", La Cruz, 1881 a, pág. 187). 
También condenaba el "laicismo" de Pidal, que consistía en querer organizar una asociación de católicos sin que hubiese sido previamente aceptada y aprobada por el episcopado. Esta advertencia a los promotores de la Unión era un claro rechazo de la libertad que tomaban los seglares católicos para organizar la política católica fuera de la Iglesia. Evidentemente esta crítica también iba dirigida a los integristas y carlistas que desde la prensa habían organizado una campaña de oposición contra algunos obispos como el de Barcelona, Urquinaona, acusado de colaboración con los "mestizos" de Pidal y con el liberalismo.

Otros serios reparos con respecto al proyecto de Pidal procedían del obispo carlista de Daulia, Josep Serra. Este prelado afirmaba que la única intención de la Unión era política y anticarlista y que estaba contagiada por el liberalismo. A sus ojos, esta "unión heterogénea" sólo quería disolver el carlismo: "Nombres de personas ilustres, de personas muy queridas, muy respetables $[\ldots]$ unidos y confundidos con nombres de sujetos que no han renunciado y no renunciarán probablemente jamás al nombre de liberales" ( $\mathrm{La}$ Cruz, 1881d, I pág. 317).

En cuanto a Salvador Casañas, obispo de Urgel, que no ocultaba su simpatía a favor de los carlistas, fue otro detractor de la Unión Católica. Salvador Casañas, que desde 1875 se había enzarzado en varias contiendas mediante la prensa con los católicos moderados "inficionados por el virus del liberalismo", denunciaba también las intenciones políticas de Pidal para acabar con el partido carlista. Las contestaciones de ambos prelados a la circular de Pidal fueron inmediatamente recogidas por la Revista Popular, así como por otras publicaciones integristas que las consideraban como un argumento más para endurecer su postura intransigente: "Este superior testimonio nos confirma más y más en la absoluta intransigencia que ha sido siempre la de nuestra revista" (R. Popular, 1881, pág. 119).

Pese a las condenas violentas de algunos prelados como los Obispos de Urgel, de Daulia y de Osma, la Unión Católica se beneficiada de la aceptación, a veces cautelosa, de la mayoría del episcopado. La postura prudente y moderada de los obispos de Barcelona, José María Urquinaona y del Arzobispo de Granada, Bienvenido Monzón, incitó el resto de la jerarquía católica a intervenir para que se sentasen las bases y el fin de la asociación, que debía ser ante todo religiosa ${ }^{6}$.

El Cardenal Moreno, arzobispo de Toledo, tomó la iniciativa y el 14 de Febrero de 1881, durante la constitución oficial de la Unión Católica, las nuevas bases de la asociación fueron formuladas con el consentimiento de la

6. El arzobispo de Toledo expresó de manera significativa cuál iba a ser el contenido de la Unión Católica: "Esta Asociación no tiene origen político, esta Asociación no tiene fines políticos; nada más distante de ella que fines políticos. Está presidida por los Señores Obispos y nosotros lo que deseamos es hacer la felicidad de nuestra patria al propio tiempo que trabajamos en defensa de los intereses de la Iglesia" ( $L a$ Cruz, 188le, pág. 425). 
jerarquía católica. Como ya señalaron otros investigadores del tema, al recibir la bendición de los prelados españoles, la Unión Católica se redujo a una asociación exclusivamente religiosa al servicio del episcopado (M. Campomar Fornieles, 1984, pág. 68).

En 1881, la Unión Católica distaba de ser un partido católico comparable a los que existían en Alemania o Bélgica y no tenía porvenir como organización política. Como resumió Sánchez de Toca, uno de los más decididos defensores del proyecto de Pidal, al hacer un balance de la trayectoria política de la Unión:

La Unión no tiene pues ninguna condición de partido político; su propia naturaleza se lo impide. Por parte tiene a su frente la jerarquía episcopal [...] y por otra parte, a diferencia de todo partido político, carece la Unión Católica de soluciones concretas en lo referente a formas e ideales de gobierno (Sánchez de Toca, 1885, pág. 300).

En ningún momento, incluso cuando tuvo su propio periódico, La Unión (1881-1887), la Unión Católica pudo ejercer influencia alguna en las masas católicas. El periódico pidalino no arrastraba a las masas católicas y se limitó a ser una publicación destinada a la intelectualidad española, a un público de "élite" (Campomar Fornieles, 1984, pág. 62).

\section{a. La Unión Católica en Cataluña. Primeras reacciones de la prensa católica catalana: el Diario de Barcelona y La Veu de Montserrat (1878-1889)}

Aunque había sido neutralizada políticamente por el episcopado, la Unión Católica fue acogida con desconfianza y hostilidad por integristas y carlistas. Las advertencias del episcopado a la prensa intransigente no evitaron que la publicística católica se convirtiese en el campo de batalla privilegiado de los íntegros?

Desde el anuncio del proyecto de constitución de la Unión Católica, el Diario de Barcelona siguió muy atentamente las diferentes fases de su evolución. Para este diario, que mantenía una postura abiertamente anti-carlista y rechazaba el integrismo, la Unión Católica aparecía como una hábil maniobra por parte de Pidal para debilitar la comunión tradicionalista ${ }^{8}$. El Diario de Barcelona se

7. Amigo de personalidades políticas como Manuel Durán y Bas, futuro ministro de justicia en el gobierno Silvela, y muy cercano al grupo de los católicos catalanes como el eclesiástico Jaume Collel y el Obispo Morgades, Urquinaona se opuso constantemente al radicalismo religioso de los católicos intransigentes. Consciente de que la Unión Católica iba a profundizar las divisiones de los católicos y preocupado por la agitación que se manifestaba en el episcopado, Urquinaona acogió la Unión con circunspección: "El pensamiento que ustedes han concebido de que todos los católicos se unan para defender los grandes intereses de la Religión [...] no puede ser más recomendable [...]. Más diré a ustedes: no es posible el verdadero catolicismo sin que entre todos los que lo profesan haya unión perfecta..." (La Cruz, I, 1881b, pág. 209).

8. "[...] Y con una oportunidad verdaderamente hábil, los pidales y otros enemigos del Sr. Nocedal y de cuanto reza con El Siglo Futuro sondearon el terreno, fueron minándolo poco a poco y cuando contaban con el asentimiento de casi todo el Estado Mayor de D. Carlos han lanzado a la publicidad la carta dirigida a Monseñor Freppel" (Diario de Barcelona, 1881a, pág. 443). 
apresuró a publicar la circular de los promotores de la Unión así como la contestación de Mr. Freppel a los católicos españoles. Varios artículos de Mañé y Flaquer resultan muy esclarecedores en cuanto a la postura del sector católico moderado y conservador catalán ante el proyecto de Pidal $^{9}$.

Profundamente impregnado por el ejemplo del partido católico belga y el del Centro alemán, que supieron adaptarse a las instituciones políticas para la defensa de los intereses religiosos, Mañé y Flaquer consideraba esperanzador el propósito de la Unión Católica: "Hemos creído siempre que era necesario separar la religión, no de la política, sino de los partidos [...]. Hoy vemos aprobado y bendecido nuestro pensamiento por los prelados españoles y no hemos de ocultar la gran satisfacción que nos causa este importante y trascendental acontecimiento" (Diario de Barcelona, 1881b, pág. 960).

A ojos de Mañé y Flaquer, el radicalismo religioso de los carlistas e integristas era responsable de las profundas divisiones del campo católico y de la situación de cisma que amenazaba a la Iglesia. La Unión Católica, para el director del Diario de Barcelona, puede constituir un medio para poner término a la "desastrosa dictadura" de carlistas e integristas (Diario de Barcelona, 1881c, pág. 4544).

En muchos punto coincidían las reacciones y reflexiones de Juan Mañé y Flaquer y de Urquinaona: el mayor obstáculo para una unión de todos los católicos era la usurpación del magisterio católico por parte de algunos "pontífices laicos y mitra y tiaras laicas". El director del Diario de Barcelona subrayaba el peligro que representaba este "segundo poder religioso" de cierta prensa intransigente, que no acataba las recomendaciones del episcopado. Mañé expresaba abiertamente su repulsa hacia el exclusivismo religioso de los intransigentes que, incapaces de olvidar "las banderías políticas", tomaron pretexto en la Unión Católica para asentar su monopolio del catolicismo y reivindicar la movilización de los católicos.

De hecho, tanto el análisis del entonces obispo de Barcelona como el de Mañé y Flaquer con respecto a la Unión Católica y a sus repercusiones en el campo católico se verificó. El fuerte arraigo del integrismo en Cataluña, al que se adhería la mayoría del clero, imposibilitaba la constitución de la Unión Católica en las diferentes diócesis catalanas. En un informe remitido por Urquinaona al Nuncio, el día 4 de Marzo de 1883, se anunciaba la decisión de descartar en algunas diócesis la organización de la Unión Católica ${ }^{10}$.

9. Estos artículos fueron publicados en 1881 en el Diario de Barcelona bajo el título "La Unión de los católicos" el 25 de Enero, pág. 960 , el 30 de Enero, pág. 1271. También resultan esclarecedores otros artículos que salieron en el Diario de Barcelona hasta finales de Abril de 1881.

10. "Debo advertir que yo, viendo la actitud tan pronunciada de los nocedalistas contra la Unión Católica, por evitar cuestiones y disgustos, me abstuve de crearla en mi diócesis, y nada he hecho en favor de ella" (Bonet y Martí, 1990, pág. 42). 
Esta postura, que excluía cualquier tipo de radicalismo religioso, era compartida también por otros católicos moderados catalanes como Torras i Bages, Jaume Collell y Eduardo Llanas. Tanto Jaume Collell como Eduardo Llanas desempeñaron un papel importante en cuanto a la difusión de un cristianismo al margen de las banderías políticas y conforme con las orientaciones más realistas y conciliadoras de León XIII Se destaca la importancia de la revista dirigida por el eclesiástico Llanas, El Criterio Católico (1884) cuyo fin era oponerse a las campañas integristas ${ }^{11}$. En cuanto a Jaume Collell, fue el fundador de la revista semanal La Veu de Montserrat que salió a la luz en 1878. Contaba con la colaboración de católicos prestigiosos como el poeta Verdaguer, el escritor Milá i Fontanals Víctor Balaguer entre otros. Esta revista, de carácter regionalista, ejerció una profunda influencia en el movimiento regionalista catalán. Muchos artículos de Collell se dedicaban a reivindicar el renacimiento de un cristianismo específico de Cataluña. A partir de 1886, publicó la importantísima obra de Torras i Bages, La Tradició Catalana. Menos combativa que El Criterio Católico cuando se trataba de intervenir en las contiendas con carlistas e integristas, La Veu de Montserrat anunció desde el principio de su publicación su intención de permanecer al margen de las polémicas políticoreligiosas ${ }^{12}$.

Jaume Collell, que pretendía, como periodista, seguir ajeno a cualquier tipo de compromiso político, abandonó en determinadas ocasiones su distanciamiento prudente. Se produjo el caso en el momento de la constitución de la Unión Católica, que desencadenó violentas posturas de rechazo y hostilidad por parte de los integristas catalanes. En 1881, la agitación y la mordacidad de la prensa intransigente eran tan fuertes que Jaume Collell se sintió obligado a comentar el proyecto de Pidal y sus repercusiones en Cataluña: "Creemos del caso decir cuatro palabras; porque si antes podía ser prudente el silencio que desde el primer momento nos impusimos, de ahora en adelante podría dar lugar a recelos o sospechas temerarias" (La Veu de Montserrat, 1881b, pág. 1) ${ }^{13}$.

Los comentarios de Collell con respecto a la Unión Católica reflejaban las orientaciones de la revista: en ningún momento debían mezclarse la actividad pastoral y el compromiso político y sólo el respeto de la autoridad episcopal podía asegurar la unión de los católicos. Como otras personalidades católicas relevantes de su época, por ejemplo Morgades, Torras i Bages, Collell era el

11. En el momento de su aparición, en Noviembre de 1884, en "Nuestro Programa", Llanas advierte que la revista no tiene la vocación "de un diario político redactado a vuela pluma y obedeciendo a las pasiones del momento sino [...] de una publicación católica en toda la extensión de la palabra".

12. "Pero ya lo hemos dicho y no nos cansaremos de repetirlo, nuestra pluma no se ha puesto al lado de nadie; sólo sirve una gran idea para la cual tenemos que trabajar si queremos conservar el espíritu catalán, el verdadero espíritu de aquella raza vigorosa, nutrida como todos los pueblos latinos en la amorosa falda de la Iglesia" (La Veu de Montserrat, 1881a, pág. 1). 
representante de un humanismo cristiano preocupado por las exigencias de una nueva época y completamente conforme con las enseñanzas religiosas y sociales de León XIII. Collell no hacía referencia a las intenciones políticas de la Unión de Pidal y afirmaba que una asociación de esta índole sólo podía funcionar bajo la autoridad del episcopado. El director de La Veu de Montserrat, de igual modo que lo hacían otros católicos moderados como Eduardo Llanas en 1884, denunciaba las prerrogativas que se otorgaban los católicos laicos en materia de interpretación de la doctrina católica. Estos laicos, afirmaba Collell, se aprovechaban de la prensa y de algunas asociaciones católicas para erigirse en jueces, al margen de la jerarquía católica ${ }^{14}$. Las hondas divisiones de los católicos, las exacerbadas polémicas provocadas por los que identificaban religión y política hacían ilusoria una asociación como la Unión Católica. En 1882, al analizar más detenidamente las causas del fracaso de la Unión, Collell constataba con cierto desencanto que, contrariamente a algunos países como Alemania, donde el Centro alemán de Windhorst supo lograr sus propósitos, en España los católicos no habían sido capaces de promover una asociación semejante por "falta de unión y de firme organización" (La Veu de Montserrat, 1882a, pág. 17).

La Veu de Montserrat, en la que se expresaron los católicos catalanes, constituyó en los años críticos de los enfrentamientos entre intransigentes y mestizos el reflejo de las nuevas orientaciones conciliadoras que se estaban fraguando en la Iglesia española bajo el impulso de León XIII.

Esta visión de la religión y de la misión de la Iglesia ante la sociedad de su época quedó plasmada en la importante obra de Torras i Bages, El Clero en la vida social moderna (1888). Activo colaborador de La Veu de Montserrat, el que llegó a ser obispo de Vich en 1889 se vio directamente implicado en las contiendas periodísticas al ser nombrado censor de la prensa en 1889 por el obispo de Barcelona ${ }^{15}$. Torras i Bages volvía a plantear el problema que tan acuciante se había vuelto durante este período y que trataba con frecuencia Jaume Collell en las páginas de su revista: ¿cuál debía ser el cometido del clero ante la sociedad moderna?

Aunque no debía manifestarse a favor de partido político alguno debe preciarse de leal y ser fidelísimo al poder civil y amigo de ayudarle cuanto pueda [...]. Nunca como ahora ha sido conveniente hacer un llamamiento a la independencia política del clero (Torras i Bages, 1948, pág. 1731).

13. La postura de Jaume Collel ante los ataques de la prensa intransigente y más especialmente de El Correo Catalán fue analizada por Bonet i Baltá y Casimir Martí, en L'integrisme en Catalunya, 1990, pp. 43-45.

14. "No se alarmen con el ruido de las desavenencias que en el campo de la prensa católica han surgido, no tengan en cuenta las disputas y polémicas de los periodistas seglares que no tienen más autoridad que la que puede darles su mérito personal" (La Veu de Montserrat, 1881b, pág. 42).

15. En una carta dirigida el 10 de Febrero de 1883 a Torras y Bages, Urquinaona ponía de relieve el carácter dramático de las polémicas entre católicos y el papel de la prensa intransigente en la crisis religiosa (Torras i Bages, 1934, pág. 271). 
El clero en la vida social moderna constituye un valioso testimonio para profundizar en las causas de los conflictos políticos religiosos que afectaban a la Iglesia española con especial gravedad en los años 1880-1882. También es el reflejo de la postura conciliadora de algunos católicos.

Estos católicos moderados, que no consideraban la Unión Católica como la única respuesta válida para la defensa del catolicismo, se expresaron en Cataluña por medio de publicaciones que surgieron a partir de 1875 , como una respuesta y un freno al militantismo exacerbado de la prensa intransigente.

\section{b. Exacerbadas polémicas en la prensa intransigente con motivo de la Unión Católica}

La Unión Católica brindó una oportunidad más a los carlistas e integristas para afirmar desde la prensa, con tono abiertamente acusatorio, su condena de los mestizos. Las numerosas publicaciones integristas catalanas que surgieron entre 1880 y 1884 se ocuparon de manera casi obsesiva de la Unión de Pidal, considerada como una maniobra por parte de los mestizos para estorbar la comunión tradicionalista ${ }^{16}$. La mayoría de esas nuevas publicaciones integristas eran semanarios satíricos, con grabados ferozmente antiliberales y claramente denigrantes con respecto a los llamados mestizos, también apodados pasteleros (La Vespa, 1882, pág. 1). La violencia verbal y la mordacidad de las críticas también se manifestaban en diarios carlistas como El Correo Catalán que, desde el principio, había declarado una guerra sin cuartel a los "transaccionistas"17 (Bonet y Martí, 1990, pp. 39-40).

A ojos de carlistas e integristas, la Unión Católica aparecía como un intento por parte de Pidal para debilitar el partido carlista en el que evidentemente existían disensiones a raíz del nombramiento de Cándido Nocedal como representante político en Madrid. La prensa carlista reflejaba estos temores. Pese a las palabras tranquilizadoras de Llauder, que afirmaba en 1882 que sólo "hay una pequeña fracción muy insignificante por el número que está separada de la masa general" (Llauder, 1882, pág. 3), las restantes publicaciones intransigentes no cesaban de denunciar las consecuencias de la maniobra pidalina ${ }^{18}$.

Todas las publicaciones intransigentes adoptaron el mismo procedimiento, que consistía en publicar sólo las pastorales y circulares de los prelados que

16. La revista integrista La Vespa (1882), en un artículo titulado "Punzadas" del 30 de Noviembre 1882, declaraba que "la Unión es una pantalla para encubrir ambiciones de los que quieren destruir el único obstáculo que se opone al compieto triunfo de la Revolución en nuestra desgraciada tierra, el tradicionalismo".

17. Entre las revistas intransigentes satíricas cabe destacar La Vespa (1882), Lo Fuet (1882), Lo Burinot (1879-1882), L'Avi Vell (1882).

18. La Vespa habla de una "liga de católicos liberales para destruir la gran comunión tradicionalista" (1882a, pág. 1). 
habían manifestado abiertamente sus reparos, e incluso su hostilidad, con respecto a la Unión Católica. Algunas revistas como La Vespa organizaron homenajes y suscripciones populares en honor de prelados intransigentes como los obispos de Osma y de Daulia. En 1881, la Revista Popular, cuya conducta era un modelo para las demás publicaciones integristas, publicó las cartas de los obispos de Granada y de Urgel con el siguiente comentario: "Este superior testimonio nos confirma más y más en la absoluta intransigencia que ha sido siempre la de nuestra revista" (1881, pág. 119).

Pero la prensa intransigente no se satisfacía sólo con publicar las cartas de los prelados adscritos a su causa. Las publicaciones integristas y carlistas declararon que pensaban utilizar "todas las armas que matan espiritualmente". Así es como se acudía a la calumnia, a la caricatura y a la crítica verbal más despiadada. Un procedimiento corriente esgrimido entonces por las revistas satíricas era la utilización de grabados caricaturescos que solían ilustrar los artículos de fondo de la primera página de la publicación. El desarrollo de esta prensa católica satírica fue importante después de 1875 y perduró hasta 1888 . Muchas de estas publicaciones joco-serias surgieron con la finalidad de oponerse a las revistas marcadamente anticlericales que, como La Campana de Gracia o El Loro, habían alcanzado tiradas muy sustanciales (Bozal, 1979, pág. 183) ${ }^{19}$.

El contenido ideológico se acentuó notablemente después de la Restauración. Muchos de los que colaboraban en dichas revistas eran miembros del clero como Ignasi Puig o Pedro Reig ${ }^{20}$.

La finalidad militante y la detracción constante eran las características más notables de una prensa que reflejaba las intensas contiendas politíco-religiosas de finales de siglo. De escasa duración ya que algunas sólo llegaron a publicarse durante un año, las revistas satíricas carlistas e integristas llegaron a tales extremos durante sus campañas de crítica y condena de los mestizos y de algunos miembros del episcopado, que tanto el Nuncio de León XIII como los obispos de Barcelona y de Tarragona tuvieron que intervenir y suspender su publicación ${ }^{21}$.

19. El periódico católico ilustrado La Campana de la Catedral, que empieza a publicarse en Enero de 1872 , reconoce en su primera publicación que quiere luchar con "la prensa inmoral y antirreligiosa". Su título evoca intencionadamente La Campana de Gracia. Lo Burinot, "periódico ilustrado y satírico", que surge en Enero de 1880 , multiplica los ataques a la prensa anticlerical joco-seria como El Diluvio o la Esquella de la Torratxa.

20. También se puede mencionar al eclesiástico Francisco Mateos Gago, colaborador de la Revista Popular y de la publicación integrista Dogma y Razón (1897), que publicó varios artículos en contra de la Unión Católica y de los prelados "cómplices del liberalismo" en la revista La Vespa (1882): “ ¿Insistirán muchos de nuestros Prelados en manifestar sus simpatías por la Unión y sus pocos disimulados desdenes a los tradicionalistas en sus Boletines, en sus Pastorales y hasta en el púlpito?", La Vespa, 30 de Noviembre de 1882.

21. En Marzo de 1882, el obispo Urquinaona, en una circular dirigida a los católicos de su diócesis, se lamenta de la situación de cisma provocada por la prensa intransigente que alimenta y exacerba los conflictos religiosos: "[...] la presunción crece y se manifiesta más erguida, prescindiendo 
A.L.E.U.A. $/ 10$

También diarios carlistas como El Correo Catalán participaban en estos ajustes de cuentas con respecto al episcopado. Al felicitar el Obispo intransigente de Osma que supo "desenmascarar" a los transaccionistas, Llauder añade que prelados como él simbolizan los valores esenciales del carlismo, y entre otros, la intransigencia.

Este lenguaje ofensivo y estos procedimientos de detracción con respecto a la jerarquía católica se manejaban constantemente en la prensa integrista de 1881 y por lo menos hasta 1888 . La prensa aparecía como el instrumento privilegiado de las contiendas entre católicos y constituía el soporte esencial de difusión de las tesis integristas ${ }^{22}$. Con publicaciones tan importantes como $E l$ Correo Catalán, la Revista Popular y con la proliferación de revistas y semanarios de orientación integrista en Barcelona pero también en provincias, el integrismo disponía en Cataluña de unos medios "logísticos" eficientes (Bonet, 1990, pág. 47). Por otra parte, si se tiene en cuenta que muchas asociaciones católicas como la Juventud Católica o la Asociación de Católicos, implantadas en algunas diócesis, eran afines al integrismo, se comprende mejor el alcance de las advertencias de algunos miembros del episcopado, que afirmaban en la mayoría del clero y gran parte de los fieles seguían las consignas integristas ${ }^{23}$.

\section{Las grandes campañas de movilización religiosa de 1881 y 1882 - Recuperación por parte de la prensa intransigente de las romerías y peregrinaciones}

A partir de 1881, con la celebración de distintos centenarios y con la organización de romerías y peregrinaciones, el sector católico intransigente

ya completamente de nuestro sagrado ministerio para interpretar documentos pontíficos, decidiéndose en tono magistral sobre asuntos de nuestra exclusiva competencia", Boletín Oficial Eclesiástico del Obispado de Barcelona, 9 de Marzo de 1882, pág. 156.

Se suspendió, en Marzo de 1882, la revista satírica Lo Fuet. En una carta dirigida a Torras i Bages en 1883, el obispo de Barcelona alude a la situación caótica de la prensa católica en Cataluña y emplea la palabra "secta" para designar a los laicos católicos y algunos miembros del clero que comparten el radicalismo religioso de C. Nocedal: "[...] realmente secta es lo que se nos ha introducido en la Iglesia de España y con tales bríos que no basta la fuerza moral para acabar con ella" (Torras i Bages, 1934, pág. 272).

22. En 1882 La Vespa afirmaba que el mundo era un campo de batalla en el que la prensa era una de las mejores armas: "Es de buen sentido que en toda guerra, uno de los enemigos se aprovecha de las invenciones y tretas del otro" (La Vespa, 1882b, pág. 2).

23. En una pastoral del mes de Marzo 1882, el obispo de Barcelona, Uquinaona, denunciaba la grave crisis que afectaba la Iglesia española y que podía llevar a un cisma. Condenaba la propensión de la prensa integrista y carlista a utilizar la calumnia y el insulto contra miembros del episcopado. El arzobispo de Tarragona, Benito Vilamitjana, en un documento que se titulaba Reglas de conducta que, en los actuales momentos de perturbacion religiosa, dan a sus diocesanos los Prelados de la Provincia Eclesiástica Tarraconense... del mes de Marzo 1882, advertía a los fieles que uno de los males que corroía la Iglesia era "el laicismo [...] que tiende a secularizar la Iglesia y a convertir al Reino de Cristo en institución humana" (La Veu, 1882d, pp. 108-109). 
emprendió verdaderas campañas de movilización contra los mestizos. Estas campañas de propaganda tenían una dimensión política. Se trataba para los integristas y carlistas de demostrar que su poder de convocatoria de las masas católicas estaba intacto y que los católicos que habían aceptado la política transaccionista de Pidal no representaban "La España de Recaredo y otros campeones de la fe católica"24. Una vez más, esta movilización se encauzó por medio de la prensa y de las asociaciones católicas en las que predominaba la orientación integrista ${ }^{25}$. Esto fue especialmente el caso en Cataluña donde, como ya se ha señalado, el integrismo había arraigado con particular vitalidad (Bonet y Martí, 1990, pp. 9-48).

En Julio de 1881, con motivo del traslado del cuerpo de Pío IX al Quirinal, los integristas quisieron demostrar una vez más que las masas católicas respondían a las consignas del sector intransigente y promovieron una peregrinación de desagravio a Roma. La organización de la romería había sido propuesta por Cándido y Ramón Nocedal, que explicitaron su proyecto más adelante en una carta a León XIII. Los términos de dicho documento revelaban de manera bastante explícita la voluntad de los promotores de la romería de dar una orientación integrista a esta nueva manifestación: "Una gran romería, pura y absolutamente católica, como la que de España fue a Roma el año 1876 y el día de Santa Teresa, se postró a los pies de Pío IX" (Revista Popular, 1882a, pág. 21).

Por otra parte, las juntas de organización de la peregrinación estaban constituidas, en su mayoría, por conocidas personalidades integristas y carlistas ${ }^{26}$. La prensa intransigente, con tono triunfalista, destacaba el carácter católico puro de las juntas organizadas " $[\ldots]$ sin ningún contubernio, ni mezcolanza con apestados de epidemia liberal" (R. Popular, 1882b, pág. 54).

También puntualizaba esta prensa que las juntas se habían constituido oficiosamente sin la aprobación previa de los prelados de las diócesis (El Correo Catalán, 1882, pág. 3). Sólo después de la constitución de las juntas, Cándido y Ramón Nocedal enviaron una carta a los prelados para que presidiesen la peregrinación. Los católicos moderados y algunos obispos que se habían visto excluidos de las juntas protestaron abiertamente. La prensa intransigente se

24. En un conocido artículo sobre la celebración del centenario de Calderón en Agosto de 1882, Sardá y Salvany proclamaba que esta celebración de los centenarios debía ser "castizamente española, o lo que es lo mismo, católica, apostólica, romana, sin mezcla de heterodoxos elementos" (Revista Popular, 1882d, pág. 65).

25. En los años 1881-1882, tanto la Juventud Católica como la asociación de San Miguel Arcángel, en Barcelona, promovieron la organización, conjuntamente con la prensa intransigente, de distintas peregrinaciones. Luis Cuenca y de Pessino, católico integrista, presidente de la Juventud Católica y colaborador de El Correo Catalán y de la Revista Popular, no oculta la orientación abiertamente integrista de la Juventud al declarar en 1882: "Esta Juventud Católica os llama de nuevo en la seguridad de ser oídos como siempre que ha levantado pendón por la causa íntegramente católica" (Revista Popular, 1882f, pág. 247). 
aprovechó una vez más de las tensiones provocadas por un acontecimiento de tipo religioso para recuperar la situación con fines políticos. La Revista Popular volvió a afirmar la postura intransigente de los promotores del proyecto: "Que no ha llegado todavía, y esperamos en la misericordia de Dios no llegará jamás, la hora de las concesiones y transacciones, sino que sigue aún [...] la de las a todo trance enérgicas resistencias" (R. Popular, 1882c, pág. 99).

En Enero de 1882, las tensiones entre católicos moderados e intransigentes habían Ilegado a tal extremo que el Obispo de Tarragona, Benito Vilamitjana, publicó un documento en el que mencionaba la situación de cisma que amenazaba a la Iglesia. Este documento era una advertencia a los integristas y más especialmente a Ramón y Cándido Nocedal, a quienes envió también una carta en la que afirmaba que de ningún modo podían los prelados "aceptar el papel de comparsas que parece ser el que se nos destina"27.

Hasta las publicaciones más moderadas, que querían mantenerse alejadas de la contienda como La Veu de Montserrat, intervinieron para enjuiciar los conflictos promovidos por la prensa integrista y carlista. Jaume Collell, al comparar la Iglesia española a un ejército derrotado, explica a sus lectores que los abusos de la prensa católica imposibilitan cualquier esfuerzo de conciliación de los católicos ( $L a$ Veu, 1882b, pp. 33-34). A partir de 1882 se multiplicaron las advertencias y hasta las amenazas por parte del episcopado con respecto a la prensa intransigente. Algunos obispos como Ceferino González, obispo de Córdoba, constatan que algunas publicaciones intransigentes son tan nefastas para la causa católica como la prensa liberal: "Si todos los periodistas y lectores de periódicos católicos hubieran tenido esto presente no lamentaríamos hoy esa profunda división de las fuerzas cristianas que contrista a los buenos y regocija a los malos" (La Veu, 1882c, pág. 2).

\section{EI "laicismo" en la prensa integrista}

En los años 1881-1882 uno de los problemas más acuciantes a ojos de la Iglesia española, y más particularmente de una mayoría del episcopado, era el "laicismo" de algunos miembros del clero y de muchos católicos seglares que desde la prensa daban y quitaban patentes de catolicismo e interpretaban los documentos pontificios. Varias razones explican la violencia con la que la

26. La junta de Madrid estaba presidida por el obispo integrista de Daulia y por Cándido Nocedal. En ella figuraban Mateos Gago, Antonio Vaibuena, Navarro Villoslada y Leandro Herrero. En cuanto a la junta de Barcelona presidida por Luis María de Llauder, se encontraban Sardá y Salvany y Luis Cuenca y de Pessino, entre otros.

27. Esta carta de Benito Vilamitjana era una contestación a Ramón y Cándido Nocedal, que habían pedido a los prelados de varias diócesis que presidieran las juntas de la peregrinación organizadas $\sin$ el acuerdo previo de la jerarquía católica (Juan Corominas, 1891, pág. 637). 
corriente integrista, que predomina entonces en el partido carlista, se opone al episcopado catalán y a los católicos moderados. En Cataluña, el fuerte arraigo del sector integrista, que abarcaba a una mayoría del clero, representó un freno constante para los tímidos intentos de adaptación social y política de la Iglesia española a la sociedad de su tiempo ${ }^{28}$. Mientras que con Pío IX los católicos intransigentes se habían beneficiado, en su condena del liberalismo, del apoyo de un poder espiritual, con León XIII la situación es distinta. León XIII aparece, para los integristas y carlistas, como el Papa de la hipótesis ya que considera la libertades modernas como un mal menor. El Pontífice, en varias ocasiones, afirma su rechazo de los católicos que identifican la defensa del catolicismo con un partido político. Con el nuevo Papa la condena del liberalismo sigue tan firme como con Pío IX; pero León XIII incita a todos los católicos a unirse y acudir a las instituciones parlamentarias para estar presentes en la vida política. Las referencias constantes del sector integrista en 1881 y 1882 a Pío IX reflejan su nostalgia de una época en la que se sentían apoyados en su radicalismo religioso. Al no poder oponerse abiertamente a la política religiosa más conciliadora de León XIII, estos católicos "íntegros" se encerraron con inusitada violencia en una postura de obstrucción contra las recomendaciones y orientaciones del episcopado.

Por otra parte, la vitalidad de la prensa intransigente y la abierta colaboración de asociaciones católicas, como la Juventud Católica o San Miguel Arcángel, representaban un eficiente instrumento de movilización de los católicos en pro del integrismo ${ }^{29}$.

Los católicos intransigentes no dejan de referirse constantemente al Syllabus y a Pío IX y proponen una interpretación de los documentos y de las encíclicas de León XIII que favorecía su postura intransigente. En el momento en que se difunde la Cum Multa de León XIII, los carlistas y mestizos utilizaron la encíclica pontificia para reforzar su radicalismo religioso, y la prensa intransigente pasó por alto las orientaciones conciliadoras contenidas en este documento ${ }^{30}$.

28. Varios testimonios de prelados catalanes recalcan el peso del integrismo en Cataluña y la aspereza de los enfrentamientos entre católicos de varias diócesis. Pueden citarse la Pastoral dirigida al clero y fieles de la provincia eclesiástica de Tarragona del 21 de Junio de 1883, B.O.E. del Obispado de Barcelona y que fue firmada por el arzobispo de Vich, los obispos de Lérida, Gerona, Urgel y Tortosa, así como la carta del eclesiástico Eduardo Llanas (Llanas, 1887, pág. 115).

29. Es significativo a este respecto el artículo publicado en la revista integrista La Vespa en 1883, que recalcaba la orientación intransigente de la mayoría de las asociaciones católicas catalanas: "Las asociaciones católicas de vida activa, que tan numerosas son en España y tan buenos frutos producen ¿quién las inspira y anima sino el partido tradicionalista?” (La Vespa, 1883, pág. 2).

30. La prensa integrista y carlista provocó una polémica tan acerba con respecto a la interpretación de la Cum Multa que la Nunciatura Apostólica tuvo que publicar una circular, dirigida a los prelados españoles, para aclarar la postura del Pontífice con respecto a las divisiones de los católicos españoles: "Algunos reverendísimos Prelados de estos Reinos se han dirigido a esta 
A.L.E.U.A. $/ 10$

\section{La Cum Multa (1882) - recomendaciones de León XIII a los periodistas católicos antes los excesos de la prensa}

La encíclica Cum Multa del 8 de Diciembre de 1882 es un documento de particular importancia por varias razones. Por una parte contiene numerosas referencias a la situación de la Iglesia española y aclara algunas de las causas de los conflictos que dividen a los católicos. Sin lugar a dudas la situación de cisma que afectaba a la Iglesia española preocupa hondamente al Pontífice, que disponía de muchas informaciones acerca de España ${ }^{31}$.

Pero esta encíclica también es importante ya que explicita la postura de León XIII con respecto a la acción religiosa de los católicos y su participación en las instituciones políticas. En la Cum Multa, León XIII condena tanto a los que "suelen no distinguir la política de la Religión" como los que "mezclan e identifican la Religión con algún partido político hasta el punto de tener poco menos que por separados del Catolicismo a los que pertenecen a otro partido" (R. Popular, 1882f, pág. 430). Indudablemente el Papa rechaza a los liberales que quieren la separación del Estado y de la Iglesia, pero también cualquier forma de radicalismo religioso. Al preconizar la concordia de todos los católicos y su intervención en la vida política, León XIII se sitúa en el terreno de la hipótesis y acepta los hechos consumados. La Iglesia y el Estado son dos potestades aparte, cada una con su misión en la sociedad.

En posteriores encíclicas como la Inmortale Dei en 1885 y Libertas en 1888 , León XIII volverá a subrayar el concepto de libertad de los católicos reflejado en la Cum Multa. La libertad bien entendida es la tolerancia con respecto a las opiniones políticas de todos en la medida en que no interfieran con la jurisdicción de la Iglesia. Lo que constituye un peligro son los excesos y la libertad utilizada contra la Iglesia. En este aspecto, las referencias a la situación de los católicos son evidentes. La causa del cisma es la negación de la autoridad de la Iglesia y de sus representantes, los prelados, por aquellos católicos que actúan al margen

\footnotetext{
Nunciatura Apostólica exponiendo la postura de sus respectivas diócesis y pidiendo instrucciones en vista de las deplorables divisiones que separan a los católicos españoles y de las ásperas polémicas, las cuales, no obstante los avisos dados por su Santidad en la Sapientísima Encíclica [...] continúan todavía en algunos puntos de España escandalizando a los fieles" (B.O.E., Obispado de Barcelona, 1883, pág. 201.)

31. Para aciarar las relaciones privilegiadas que existían entre la Iglesia española y Roma, cabe tener en cuenta la abundante corespondencia entre el arzobispo de Vich, Morgades y Mr. Palloti, representante de la Curia romana en España. En dos cartas confidenciales dirigidas al Secretario de Estado de León XIII, Morgades analiza los diferentes momentos de la crisis políticoreligiosa española. En su contestación a Morgades, Mr. Palloti le consulta acerca de una posible intervención en España del Papa, mediante una encíclica u otro documento. Sin lugar a dudas el extenso informe enviado por Morgades a Mr. Palloti en Septiembre de 1882 fue una valiosa aportación para León XIII acerca de la situación de los católicos españoles y en el momento de preparación de la Cum Multa.
} 
del episcopado y usurpan su magisterio: "El fundamento de esta discordia es en la sociedad cristiana el mismo que en toda república bien establecida, a saber la obediencia a la potestad legítima, que ora mandando, ora prohibiendo, ora rigiendo, hace unánimes y concordes los ánimos diferentes de los hombres" (lbíd).

Consciente de las graves tensiones que perturban la Iglesia española, León XIII hace una advertencia a los católicos "rebeldes" que no acatan la autoridad del episcopado y al clero que pretenden interpretar los documentos episcopales y pontificios: "[...] No corresponde a su deber el que los sacerdotes se entreguen completamente a las pasiones de partidos, de manera que pueda parecer que más cuidado ponen en las cosas humanas que en las divinas" (Ibíd). Al subrayar el origen de los conflictos, el Pontífice precisa cuál debe ser el papel de la prensa y de las asociaciones católicas. En cuanto a las publicaciones católicas, "deben estar sometidas a los Obispos y hacer grandísima estima de su autoridad y protección” (Ibid, pág. 431).

En anteriores ocasiones el Pontífice había destacado la importancia de la prensa católica para la defensa de los intereses de la Iglesia. Con la Cum Multa, León XIII reconoce la imposibilidad de la prensa católica para organizarse y competir eficazmente con la prensa liberal. Deplora la excesiva politización de muchas publicaciones cuya dimensión militante y polémica agudiza los conflictos y esteriliza cualquier esfuerzo para fomentar una prensa católica estructurada y duradera.

Las directrices moderadas de León XIII contenidas en la Cum Multa no apaciguaron los conflictos que dividían a los católicos. Defraudados por la postura conciliadora del Papa, los integristas se resistieron a corregir los excesos de su actuación política y a moderar la violencia de la prensa intransigente. Con pretexto de la difusión de la Cum Multa, los integristas emprendieron desde la prensa una nueva campaña contra los mestizos. Sin desautorizar abiertamente a León XIII, reclamaron el derecho a defender un catolicismo "puro" que fuese la aplicación del Syllabus.

\section{a. Reacciones de la prensa integrista con respecto a la Cum Multa}

En 1882, el Nuncio Apostólico en España reconocía que la Cum Multa no había logrado resolver la profunda discordia religiosa y que "no obstante los avisos dados por su Santidad, [los conflictos] continúan todavía en algunos puntos de España escandalizando a los fieles".

Los carlistas e integristas no quisieron conceder una importancia desmesurada a la encíclica pontificia y algunas publicaciones como la Revista Popular la publicaron casi sin comentarios. Cuando el episcopado español envió un mensaje de adhesión a León XIII, la Revista Popular publicó una serie de artículos 
en los que exhortaba a los católicos "puros" a seguir "el combate de la vida" con términos que reflejaban el más absoluto radicalismo religioso ${ }^{32}$.

El mismo lenguaje se encuentra en otras publicaciones que, como La Vespa, afirman que la encíclica es una clara condena de los mestizos y que "sólo una bandera es la buena", en este caso, la de los católicos intransigentes. La ofensiva desencadenada por la Revista Popular y La Vespa es alimentada por otras publicaciones intransigentes que como Lo Bon Catolich, acusan al Diario de Barcelona de desnaturalizar la Cum Multa al presentarla como un intento de conciliación por parte de León XIII (Lo Bon Catolich, 1883, pág. 2).

Para la prensa integrista, la encíclica desautoriza a los mestizos y sus publicaciones, "que creían que la Encíclica era una mordaza puesta en los labios de los escritores católicos [...], que creían que éstos podrían continuar haciendo la guerra al partido tradicionalista, sin que éstos se atrevieran a decir esta boca es mía" (Lo Bon Cristiá, 1883, pág. 1).

El sector intransigente parece haber ignorado deliberadamente la censura contenida en la encíclica con respecto al radicalismo religioso. Los acontecimientos posteriores confirmaron la conducta partidista de estos católicos, que preferían referirse a Pío IX más que a León XIII y que siguieron interpretando las pastorales y los documentos episcopales de acuerdo con su credo político-religioso.

De hecho la Cum Multa, que pretendía fomentar la pacífica convivencia de los católicos españoles, fracasó ${ }^{33}$. El incidente del Cardenal Pitra en 1885, que puso de relieve la clara preferencia de los integristas españoles y ultramontanos franceses por Pío IX, el tono triunfalista de la prensa intransigente con ocasión de la publicación de El liberalismo es pecado de Sardá y Salvany en 1884, reflejaron la voluntad de estos católicos de ignorar el cambio de actitud que había empezado a manifestarse en la Iglesia española desde 1878.

\section{b. La publicación de El liberalismo es pecado (1884) agudiza los conflictos de la prensa católica}

La publicación en 1884 de la polémica obra del eclesiástico integrista Sardá y Salvany dio un nuevo impulso al sector intransigente. Publicado por

32. "No hay el recurso aquí de declararse neutral. La ley divina mándale empuñar las armas en su defensa; no hacerlo es y con esto solo declararse del bando contrario. No cabe por lo mismo pensarlo, [...] ni andarse ideando trasacciones" (R. Popular, 15 Marzo 1883, pág. 163).

33. En una Pastoral dirigida al clero y fieles de la provincia eclesiástica de Tarragona, del 21 de Junio de 1883, el arzobispo de Vich, los obispos de Lérida, Gerona, Urgel y Tortosa reconocen el fracaso de las orientaciones conciliadoras de Léon XIII en España y más particularmente en Cataluña: "Ni las venerandas enseñanzas de la Santa Sede, ni las medidas dictadas por los Prelados para conjurar los males de la Religión y de la moral, y restablecer entre los católicos españoles la obediencia jerárquica y la mutua caridad tan quebrantada entre nosotros [...] han dado el resultado apetecido $[\ldots] "$ ". 
entregas desde 1883 en El Semanario de Tortosa y El Correo Catalán, este opúsculo tenía según palabras de Sardá una finalidad batalladora ${ }^{34}$.

Sin detenernos en un análisis pormenorizado de la polémica suscitada por la publicación de El liberalismo es pecado, nos interesa subrayar la concepción del periodismo desarrollada por Sardá y Salvany en su opúsculo. En 1884, las disputas entre mestizos e intransigentes habían alcanzado su punto álgido. La integración definitiva de la Unión Católica en el sistema político de la Restauración, las medidas tomadas por ciertos miembros del episcopado español contra de los integristas y la intervención del Nuncio de León XIII para corregir algunas interpretaciones confusas y partidistas de la Cum Multa por parte del sector intransigente habían enardecido los ánimos de carlistas e integristas.

La virulencia de la prensa integrista encontró un terreno abonado en los enfrentamientos apasionados desencadenados por el folleto de Sardá. De hecho El liberalismo es pecado ilustraba perfectamente la concepción militante y el papel de movilización de la prensa intransigente.

En su opúsculo, Sardá enunciaba reglas y recomendaciones para desenmascarar a los católicos-liberales y describía los numerosos casos de complicidad liberal (Sardá, 1884, pág. 60). Las alusiones críticas a los miembros del clero que colaboraban en publicaciones liberales constituyeron para Sardá la oportunidad de hacer un ajuste de cuentas con eclesiásticos moderados como Eduardo Llanas, Jaume Collell e Ildefonso Gatell que desde sus respectivas publicaciones denunciaban las campañas integristas.

En la "cruzada" anti-liberal preconizada por el eclesiástico integrista, la prensa se convierte en un instrumento de combate privilegiado. En su apología de la intolerancia, Sardá afirma que al no poder matar al enemigo materialmente, convienen destruirlo "espiritualmente": "Así en guerra justa, como se hieren y matan hombres por el servicio de la patria, se pueden herir y matar hombres por el servicio de Dios" (Ibíd, pág. 80).

No se trata para los periodistas católicos de respetar un estilo académico, ni de proporcionar informaciones de manera neutral. Al utilizar esta nueva "cátedra" que le proporcionaba la prensa, el periodista debe suscitar las pasiones y movilizar a sus lectores: "Sólo se emocionan con la literatura calurosa y encendida y apasionada. No es malo el apasionamiento producido por la santa pasión de la verdad" (Ibíd, pág. 83).

Pese a su total rechazo de mezclar las publicaciones religiosas con asuntos políticos, Sardá reconoce que la prensa debe fomentar en el público una

34. Para un estudio exhaustivo de la publicación de El liberalismo es pecado, y de su alcance en el contexto religioso y político de finales del siglo XIX, ver la excelente aportación de Joan Bonet y Baltá y Casimir Martí en L'integrisme en Catalunya. 
adhesión afectiva y también ideológica. Recalca esta dimensión ideológica de la prensa intransigente a lo largo de varios capítulos dedicados al periodismo católico y compara a los periodistas con "soldados" que se deben luchar en "una guerra sin cuartel" 35 .

Las armas de todo verdadero "soldado" de la prensa son el sarcasmo, la calumnia. Para justificar "las intemperancias del moderno periodismo", Sardá recurre a ejemplos de grandes predicadores "íntegramente católicos" que, para desautorizar al enemigo, no vacilaban en invectivarle y cubrirle de insultos (Ibíd, pp. 84-85).

Es significativo notar la importancia concedida por el autor del opúsculo al lenguaje, ya que "las palabras vienen a ser la fisonomía exterior de las ideas" (pág. 51). No en balde sabían los integristas la importancia de los términos que utilizaban para designar a los católicos moderados. La horrorosa confusión de criterios provocada en la prensa católica por las apelaciones de mestizo, neo, pastelero, transaccionista, pidalista, había hecho aún más difícil la convivencia de los católicos de finales de siglo.

La intolerancia y la violencia reivindicadas por Sardá eran las principales características de la prensa intransigente desde 1875. La publicación de El liberalismo es pecado en 1884 no hizo más que reforzar el radicalismo religioso de muchas publicaciones católicas como El Correo Catalán y las revistas satíricas ya mencionadas. En 1885, con la publicación de un artículo polémico en El Siglo Futuro, referente a las atribuciones religiosas y políticas del Nuncio Apostólico, se organizó una nueva campaña integristas que ilustraba uno de los principios defendidos por Sardá y Salvany, que afirmaba que al combatir el error, la prensa católica tenía el derecho de "encarnizarse en la personalidad del que lo sustenta"36.

\section{La encíclica Inmortale Dei: otra iniciativa por parte del pontífice para acabar con los enfrentamientos entre católicos}

La encíclica Inmortale Dei del 1 de Noviembre de 1885 aparece en un contexto de fuertes tensiones religiosas. La contienda entre integristas y católicos moderados se había agudizado a raíz de la publicación del folleto El liberalismo

35. Estos capítulos son "De la sana intransigencia católica en oposición a la falsa caridad liberal" (XXI); "De la caridad en lo que se llama las formas de polémica [...]" (XXII); "Si es conveniente al combatir el error, combatir y desautorizar la personalidad del que lo sustenta y propala" (XIII).

36. En 1885 un grave acontecimiento protagonizado por la prensa integrista obligó a los representantes del Vaticano en España a intervenir para atajar las polémicas entre católicos. Se trataba de un artículo publicado en El Siglo Futuro del 9 de Marzo de 1885 en el que Francisco María de las Rivas ponían en entredicho la autoridad del Nuncio. 
es pecado (Bonet Martí, pp. 331-389). La denuncia por parte de algunos miembros del episcopado catalán como Morgades, obispo de Vich, de la infiltración de las orientaciones integristas en los seminarios y asociaciones católicas y del papel de cierta prensa católica en las campañas y manifestaciones intransigentes, ponían en evidencia el impacto que tenía el integrismo sobre el clero y los fieles de muchas diócesis. La Inmortale Dei, en la que León XIII planteaba el problema de la actitud de los católicos ante las constituciones y libertades modernas, había sido anunciada por la prensa católica española como un documento contra el liberalismo bajo todas sus formas (Ibíd, pág. 392).

Una vez más un documento pontifico iba a convertirse en fuente de distintas interpretaciones. La Encíclica de 1885, que precisaba los derechos y los fines de la sociedad civil, las relaciones de la Iglesia con la civilización moderna y la libertad "sana y legítima" de los católicos y su derecho de participación en la vida política, fue acogida con regocijo por parte de los católicos moderados, que la consideraban como una confirmación de la hipótesis. Llanas dedicó numerosos artículos a la encíclica que fueron publicados en $E l$ Criterio Católico de Noviembre de 1885 hasta Mayo de 1886. En su glosa de la Inmortale Dei, Llanas subrayaba la importancia concedida por el Pontífice a los principios de caridad y tolerancia y "la honesta diversidad de opiniones" que podía existir entre los católicos.

En cuanto a las advertencias de León XIII a la prensa católica que "se alimenta de polémicas intestinas y cuestiones partidistas", reflejaban para el eclesiástico Eduardo Llanas una condena del sector más intransigente.

Esta lectura de la encíclica también fue la del episcopado español, que envió un mensaje de adhesión a León XIII. Numerosos prelados que habían sido hostigados personalmente por los integristas vieron con la difusión de la encíclica una ocasión para manifestar públicamente su apoyo a la postura tolerante y moderada de León XIII. En el mensaje enviado al Pontífice, el episcopado hacía referencia sin rodeos a las polémicas y contiendas de ciertas diócesis en las que el clero y los fieles confundían la doctrina católica y los asuntos políticos. Denunciaban la arrogancia de la prensa católica intransigente que quería atribuirse el monopolio del magisterio católico:

Ningún periódico, revista, folleto o publicación de cualquier género, sea cual fuere la autoridad que prestarles pueda el nombre de sus respectivos autores, tiene la misión de calificar, y menos de definir, si tal o cual teoría y opinión cabe o no dentro de la doctrina católica (Boletín Oficial Eclesiástico, 1885, pág. 28).

Este mensaje a León XIII fue denunciado por la prensa carlista e integrista como una "manifestación política" por parte del episcopado. Algunas publicaciones como Lo Crit de la Patria y El Correo Catalán afirmaron que la presencia de miembros del episcopado en los funerales de Alfonso XII constituía 
A.L.E.U.A. $/ 10$

una prueba de adhesión a la Regencia. En general la prensa intransigente hizo una interpretación de la encíclica favorable a la postura integrista ${ }^{37}$.

La Inmortale Dei no tuvo el efecto conciliador que esperaba el episcopado. En 1887, Morgades, obispo de Vich, en una circular publicada el 15 de Abril de 1887, reconocía la situación de graves desórdenes que persistía en Cataluña y que podía achacarse en gran parte a la prensa intransigente:

[Cataluña se ha convertido] en un foco permanente de rebelión y discordia, constantemente atizado por una prensa periódica que, confundiendo la insolencia con la intransigencia, fomenta un espíritu de indisciplina tal entre los católicos [...] que si no llega a tiempo el remedio, ha de producir frutos amargos para la Iglesia, como ya está actualmente causando gravísimos perjuicios a la causa de la verdadera restauración social del Reinado de Jesucristo (La Dinastía, 1887).

Sin embargo, ya desde 1885 aparecen las primera brechas en las filas del sector católico intransigente. Anunciadores de la ruptura entre integristas y carlistas en 1888 , los enfrentamientos que se producen en 1885 iban a modificar notablemente el paisaje político-religioso español.

\section{1888-1890: progresiva marginación del integrismo y agotamiento de la prensa católica carlista e integrista}

\section{a. La ruptura entre carlistas e integristas}

La ruptura entre carlistas e integristas en 1888 es la culminación de un largo proceso de exacerbación de las tensiones entre dos orientaciones distintas, presentes en el partido carlista desde 1871 . No es nuestro propósito detallar en estas páginas las divergencias doctrinales y los conflictos personales que motivaron la ruptura. Este período de la historia política-religiosa española merecería por sí solo un estudio exhaustivo ${ }^{38}$.

De 1871 hasta 1885 predominó en el partido carlista la postura de absoluta intransigencia de Cándido Nocedal con la que se había identificado la mayoría de las publicaciones carlistas. Esta radicalización constante del partido y su rechazo de cualquier tipo de participación en la vida política nacional después de 1876 desembocaron, en 1885, en una grave crisis. En esta fecha, la muerte

37. Son significativas a este respecto los artículos Te Deum Laudamus (19 de Noviembre de 1885), pp. 325-328, y Tesis, antítesis y hypótesis (3 de Diciembre de 1885), pp. 358-360 en la Revista Popular.

38. Cabe señalar que esta cuestión ha sido extensamente tratada por Gómez Aparicio en su Historia del periodismo español, capítulo VIII, pp. 311-333. 
de Cándido Nocedal planteó un problema de sucesión que no pudo resolverse inmediatamente. Un sector más moderado del partido carlista abogaba entonces por un cambio de orientación de la política del partido. A la muerte de C. Nocedal, Don Carlos tomó personalmente la dirección del partido. Otro síntoma revelador del cambio que se estaba produciendo fue la reintegración del periódico $\mathrm{La} \mathrm{Fe} \mathrm{(1876)} \mathrm{a} \mathrm{las} \mathrm{filas} \mathrm{de} \mathrm{la} \mathrm{prensa} \mathrm{carlista.} \mathrm{Diario} \mathrm{de} \mathrm{Cataluña,}$ periódico integrista que se empezó a publicar el 27 de Julio de 1888 , y cuyo director era José Pallés y Beltrán, denunciaba la presencia de $\mathrm{La} \mathrm{Fe}$ como una maniobra del sector carlista moderado ${ }^{39}$.

A partir de aquel momento, El Siglo Futuro y su director Ramón Nocedal, tomando pretexto de los indicios que reflejaban una voluntad de renovación del partido, desencadenaron una verdadera ofensiva contra el sector carlista moderado e, indirectamente, contra Don Carlos. En opinión de El Siglo, Don Carlos, presionado por el sector "acomodaticio", sacrificaba los principios antiliberales e intransigentes que habían regido el partido desde la Restauración. La consecuencia de las campañas de El Siglo Futuro y otras publicaciones integristas como la Revista Popular y Dogma y Razón (1887) fue la carta de Don Carlos enviada desde Gratz el 4 de Junio de 1888 a Ramón Nocedal, en la que se excluía oficiosamente a los integristas del partido.

A principios de Julio de 1888 , el periódico integrista de Pamplona $E l$ Tradicionalista (1886) organizó nuevas hostilidades contra Don Carlos y su partido. En un artículo insultante para los carlistas, El Tradicionalista reivindicaba el término de "tradicionalista" para los católicos que no habían traicionado la doctrina integrista y comparaba el partido carlista con la Unión de Pidal ${ }^{40}$.

Después de la exclusión de El Tradicionalista del partido y de la publicación del Manifiesto a mis leales de Don Carlos, las publicaciones integristas difundieron un documento, Manifestación de la prensa tradicionalista, en Agosto de 1888, muy esclarecedor en cuanto a las divergencias doctrinales entre el carlismo y el integrismo. Este manifiesto de la prensa integrista firmado por 24 publicaciones intransigentes era la primera etapa hacia la constitución del partido integrista.

\section{b. Agotamiento de la prensa integrista}

Desde su ruptura con el partido carlista en 1888 , el sector integrista había entrado en una fase de progresiva marginación. Los datos más esclarecedores a este respecto son los que se refieren a la evolución de la prensa desde $1888 . \mathrm{La}$ mayoría de las publicaciones católicas que se habían adherido a la postura de

39. "Muerto empero D. Cándido Nocedal, cobraron los mestizos nuevos bríos; y aquellos mismos que habían sido integrados por D. Carlos como un puñado de díscolos al desprecio de los leales, lograron penetrar otra vez en las regiones oficiales" (Diario de Cataluña, 1888, pág. 1).

40. Este artículo fue publicado después por Dogma y Razón (1888, pp. 305-306). 
Ramón Nocedal y habían entrado en el partido integrista acabaron por desaparecer progresivamente. La existencia efímera de algunos diarios y revistas que surgieron en Cataluña en los años 1887 y 1888 es significativa con respecto al cometido militante y de "púlpito ideológico" desempeñado por dicha prensa. Pueden citarse el caso de periódicos como El Integrista de Gerona que surgió en 1888 y no pasó de algunos meses. También ocurre lo mismo con El Eco de Queralt (1888) y El Seminario de Bisbal (1888) que tuvieron un breve destello de vida en los momento cruciales de la contienda entre carlistas e integristas ${ }^{41}$. Otras publicaciones como el Diario de Cataluña (1888-1891) desaparecen para resurgir bajo otro título. En cuanto a los diarios y revistas integristas que aparecieron después de 1888, no prolongaron mucho tiempo su publicación. $L a$ Tradición Catalana, que sale a la luz en 1893 dejó de publicarse aquel mismo año. Parece ser que sólo la Revista Popular perduró hasta después de 1900 aunque, a partir de 1888 , su tirada experimentó un fuerte bajón ${ }^{42}$.

Esta evolución de la prensa integrista en general refleja la pérdida de vitalidad del integrismo de 1888 a 1900 . Varios testimonios parecen confirmar este hecho. En una correspondencia confidencial, en 1894, entre el obispo de Vich, Morgades y Mr. Cretoni, Nuncio Apostólico, se advierte que, aunque perduran muchas tensiones entre los católicos, "la ruptura entre los carlistas e integristas disminuyó la intensidad de la lucha [...]. Al no haber ocurrido la división que he significado ya entre carlistas e integristas, estaríamos imponderablemente peor de lo que estamos [...]. El calor ha disminuido gracias a Dios, pero no hay duda que bajo las cenizas hay ascuas"

La constatación final de Morgades al referirse en su carta a la "horrible lucha" que había dividido a los católicos puntualiza que, después de 1888 , la situación había experimentado un cambio importante: "Mi obispado era sin duda uno de los más perturbados; por haber obrado a tiempo en la conformidad expresada, doy gracias a Dios de poder decir con toda verdad que es ahora uno de los más tranquilos [...]. Sin duda que todos no estarán convictos, pero guardan silencio y esto basta para que no haya perturbación".

Otro testimonio es el de Eduardo Llanas. En uno de los últimos números de El Criterio Católico, Llanas admite que el equilibrio de las fuerzas católicas ha cambiado y que por lo tanto ya puede interrumpirse la publicación de la revista: "Nuestro periódico hubo de convertirse en arma de combate y mientras ha sido menester combatir, no hemos faltado a nuestro puesto de honor [...]. Hoy la situación ha cambiado" (El Criterio Católico, 1888, pág. 553).

41. El Semanario de Figueras, El Semanario de Tortosa se publican sólo unos meses.

42. En un editorial titulado Muy importante, el 24 de Diciembre de 1889, Sardá y Salvany reconoce que, desde 1888 , la tirada anual de la revista s6́lo es 7.000 ejemplares.

43. Morgades, Cartas del 7 al 16 de Noviembre de 1894, Seminario de Historia Contemporánea de la Iglesia en Cataluña, dirigido por Joan Bonet i Baltá. 
Por lo que respecta a la prensa carlista, pese a la expulsión en 1888 de muchas publicaciones que se declararon abiertamente integristas, parece que gozaba de cierta vitalidad:

"La prensa [carlista] es importante [...] porque además de los periódicos de la Corte cuenta con varios en poblaciones subalternas, y entre lo propio y copiado, sobra para mantener la rebelión" ${ }^{44}$.

Según datos publicados en el Boletín de Buenas Lecturas de 1904, El Correo Catalán es una de las publicaciones que más suscripciones tiene en las distintas diócesis catalanas, seguida por la revista carlista La Hormiga de Oro, también dirigida por Luis María del Llauder (Boletín de Buenas Lecturas, 1904, pp. 2628).

En 1904, la primera Asamblea Nacional de la Buena Prensa que tuvo lugar en Sevilla recalcó en una de sus numerosas conclusiones la necesidad para la prensa católica de abandonar su protagonismo en las cuestiones políticoreligiosas y su obligación de "hablar siempre con respeto de las personas e instituciones eclesiásticas y religiosas".

A lo largo de la segunda mitad del siglo XIX, la prensa católica fue el reflejo de distintos grupos ideológicos. Utilizada como un instrumento de poder religioso y político por carlistas e integristas, esta prensa tenía una dimensión ante todo militante y combativa. Se benefició de la movilización y colaboración del clero, que en Cataluña se adhería en su gran mayoría al integrismo. Presente y activo en los seminarios y en las asociaciones de católicos, este clero ejerció un notable protagonismo para la difusión del integrismo. Es de notar la colaboración, en dicha prensa, de los políticos católicos que con sus luchas intestinas la transformaron en tribuna política. La prensa católica no sólo refleja las divisiones de los católicos, sino que también las recogía e incluso las agravaba.

\section{BIBLIOGRAFÍA}

Boletín de Buenas Lecturas. 1904. "Nota de las hojas, folletos, libros repartidos y nuevas suscripciones logradas para los periódicos católicos por las juntas de la Buena Prensa y parroquias de nuestra diócesis", Noviembre, pp. 26-28.

Boletín Oficial Eclesiástico del Obispado de Barcelona. 1883. "Instrucciones de la Nunciatura Apostólica a los Prelados de España, pp. 201-208.

44. Correspondencia del 16 de Noviembre de 1894 entre Morgades y Mgr. Cretoni, Archivo del Seminario de Historia Contemporánea de la Iglesia de Cataluña, consultada gracias a la amabilidad de su director, Joan Bonet i Baltá. 
- 1885. "Documentos que los Prelados reunidos en Madrid con motivo de las honras fúnebres que allí se han celebrado por el alma del malogrado Rey D. Alfonso XII dirigen a los fieles de su diócesis", 20 de Diciembre, pp. 28-30.

Bon Catolich, Lo. 1883. "Errores en que ha caído el Diario de Barcelona desde el 10 de Agosto de 1883", 14 de Junio, pág. 2.

Bon Cristià, Lo. 1883. "La mesticería ante la encíclica", 5 de Julio, pág 1.

BONET I BALTÁ, Joan, MARTÍ, Casimir. 1990. L'integrisme en Catalunya. Les grans polèmiques: 1881-1888, Barcelona, Editorial Vicens Vives.

BOZAL, Valeriano. 1979. La Ilustración gráfica del siglo XX en España, Madrid, Alberto Corazón Editor.

CAMPOMAR FORNIELES, Marta. 1984. La cuestión religiosa en la Restauración. Historia de los heterodoxos españoles, Santander, Sociedad Menéndez Pelayo.

Correo Catalán, El. 1882. "Crónica", 9 de Marzo, pág. 2.

COROMINAS, Juan. 1891. Pastorales del Excelentísimo e Ilustrísimo Benito Vilamitjana, Tarragona, Establecimiento Tipográficos de F. Arise.

Criterio Católico, El. 1882. “A nuestros amigos”, 3 de Noviembre, pp. 553-554.

Cruz, La. 1881a. "Circular de los representantes de la Unión Católica en Madrid a los Señores Obispos”, pág. 187.

- 1881b. "Contestación del Señor Obispo de Barcelona a los Señores representantes de la Unión Católica”, pág. 209.

— 1881c. "Respuesta del Señor Arzobispo de Granada”, pág. 215.

- 1881d. "Contestación del Obispo de Daulia a los representantes de la Unión Católica", pág. 317.

- 1881e. "Sesión general extraordinaria de la Unión Católica, celebrada el 28 de Mayo de 1881 ", pág. 425.

Diario de Barcelona, 1881a. "Correspondencias particulares", 11 de Enero, pág. 443.

- 1881b. "La Unión de los Católicos", 22 de Enero, pág. 960.

— 1881c. "El sentimiento religioso y la pasión de partido", 17 de Abril, pág. 4544.

Diario de Cataluña. 1888, 13 de Agosto, pág. 1.

Dinastía, La. 1887. "Un documento notable", 15 de Abril.

Dogma y Razón. 1888. "Cuenten con nosotros", 10 de Julio, pp. 305-306.

GÓMEZ APARICIO, Pedro. 1971. Historia del periodismo español, Madrid, Editora

Nacional, vol. I. 
LLANAS, Eduardo. 1887. Exposición a León XIII acerca de la actual crisis religiosa por varios católicos españoles, Barcelona, Tipografía de la Casa Provincial de Madrid.

LLAUDER, Luis María de. 1882. "Justicia y Paz", El Correo Catalán, 19 de Marzo, pág. 3.

Revista Popular. 1881. "Crónica general", 17 de Febrero, pág. 119.

- 1882a. "Muy importante", 12 de Enero, pág. 21.

- 1882b. "La próxima peregrinación", 26 de Enero, pág. 54.

- 1882c. "“A Roma, a Roma!”, 16 de Febrero, pág. 99.

- 1882d. "Nuestros centenarios", III, 3 de Agosto, pág. 65.

-1882e. "Nuestros centenarios", IV, 10 de Agosto, pp. 81-82.

- 1882f. "Obispado de Barcelona", 12 de Octubre, pág. 247.

- 1883. "El combate de la vida", 15 de Marzo, VI, pág. 163.

SÁNCHEZ DE TOCA, Joaquín. 1885. Ensayo sobre política y religión, Madrid, Imprenta de F. Maroto e Hijos.

TORRAS I BAGES, Joseph. 1934. Obres Completes, Barcelona, Biblioteca Balmes.

- 1948. "El clero en la vida social moderna", Obres Completes, Barcelona, Biblioteca Perenne, pp. 1687-1737.

Vespa, La. 1882a. "El cisma", 26 de Abril, pág. 1

- 1882b. "Al pan, pan, y al vino, vino”, 14 de Junio, pág. 2

- 1882c. "Manyas y flaquesas", 29 de Diciembre, pp. 1-2

- 1883. "Los católicos, ¿dónde están?" 23 de Marzo, pág. 2.

Veu de Montserrat, La. 1881a. "Tornemhi", 8 de Enero, pág. 1.

— 1881b. "Bandera blanca", 12 de Febrero, pág. 42.

- 1882a. "¿Por qué nos aprendemos?”, 21 de Febrero, pág. 17

- 1882b. "Calma y coraje", 14 de Febrero, pp. 33-34.

- 1882c. "Pastoral del Obispo de Córdoba", 25 de Febrero, pág. 50.

- 1882d. "Reglas de conducta cristiana...", 8 de Abril, pp. 108-109. 